\title{
Results of a Screening Study of Tumor Markers (REA, CA19-9, PSA, CA15-3) among the Population in South Yakutia
}

\author{
Ulyana D. Antipina, PhD*; Sardana V. Markova, PhD; Natalia V. Borisova, $\mathrm{PhD}, \mathrm{ScD}$; \\ Sardana N. Alekseeva, PhD; Irina Sh. Malogulova, PhD; Tyuaara P. Sivtseva, PhD; \\ Vera N. Yadrikhinskaya, PhD; Evgenia E. Yadrikhinskaya
}

M. K. Ammosov North-Eastern Federal University

Yakutsk, the Republic of Sakha (Yakutia), Russia

\begin{abstract}
Early cancer screening is the most effective way to reduce cancer mortality. The number of potentially viable tumor markers (TMs) is rapidly expanding and promises further improvement in sensitivity and specificity. The article presents the results of a population-based study of screening for the most common types of cancer in individuals living in South Yakutia. (International Journal of Biomedicine. 2019;9(3):220-222.)
\end{abstract}

Key Words: cancer $\bullet$ pathology $\bullet$ oncology $\bullet$ screening research $\bullet$ damage

\section{Introduction}

In 2014, WHO made a disappointing forecast that in the next 20 years the number of cancer patients would increase by about $70 \%$. In 2018 , according to the WHO, 9.6 million people died of cancer. Russia ranks fifth in the number of deaths from cancer, after China, India, the United States and Japan. ${ }^{(1)}$ Early cancer screening is the most effective way to reduce cancer mortality. The number of potentially viable tumor markers (TMs) is rapidly expanding and promises further improvement in sensitivity and specificity. TMs reflect the body's tumor burden, and subsequently increase with progressive or recurrent disease, decrease with response to treatment, and normalize with remission. ${ }^{(2)} \mathrm{TMs}$ are assuming a growing role in all aspects of cancer care, from initial screening to follow-up after treatment. ${ }^{(3,4)}$ However, it is necessary to approach very individually, and to interpret the results of tumor marker indicators together with data from other studies, such as ultrasound, MRI and biopsy.

According to the statistics of the Ministry of Health of the RF, the majority of malignant tumors detected in 2017 were in the first $(29.8 \%)$ and second $(25.8 \%)$ stages. According to the standardized indicators of 2018, Russian men most

*Corresponding author: Uliana D. Antipina, PhD. Medical Institute, M. K. Ammosov North-Eastern Federal University. Yakutsk, the Republic of Sakha (Yakutia), Russia.E-mail: uldanti@mail.ru often suffer from lung cancer (48.2 per 100 thousand of the population) and prostate cancer (39.4 per 100 thousand of the population); Russian women most often suffer from breast cancer: 53.6 per 100 thousand of the population.

According to statistical data for the Far Eastern Federal District, there are an average of 1985.2 people with cancer per 100 thousand population: 2709.3 in Kamchatka Krai, 2349.5 in the Sakhalin region, 2280 in Primorsky Krai, 2206.2 in Zabaykalsky Krai, 2204.7 in Khabarovsk Krai, 2140.4 in the Amur region, 1945 in the Jewish Autonomous Region, 1778.5 in the Magadan region, 1690.7 in the Republic of Buryatia, 1290.6 in the Chukotka Autonomous Region, and 1242.1 in the Republic of Sakha (Yakutia). ${ }^{(5)}$ According to the statistics, along with gender differences, there are also territorial ones, which indicate a set of factors determining cancer development. Regional cancer incidence can be reliably attributed to such factors as the environmental stress due to the development of industry (anthropogenic pollution of the environment, clean water problems, radon pollution, etc.). Now the most urgent need is a radio-hygienic survey of South Yakutia, as the most industrialized territory, with a high content of natural radionuclides.

In this regard, we conducted a screening study of the adult population of the Tommot city in Aldan district and Chulman village in Neryungri district to detect changes in TM levels: cancer-embryonic antigen (CEA), cancer antigen (CA) 19-9, PSA, and CA15-3. 


\section{Materials and Methods}

A total of 219 adults were examined: 77 (9 men and 68 women in Tommot (the Aldan district) and 142 (26 men and 116 women) in Chulman (the Neryungri district). The levels of TMs (CEA, CA19-9, PSA, CA15-3) in the blood serum were determined by ELISA on a Multiskan FC microplate photometer (Thermo Fisher Scientific, USA) using the VectorBest test systems (Russia). Statistical analysis was performed using SPSS (version 19.0).

\section{Results}

The study results are presented in Tables 1 and 2. The mean levels of studied TMs in the blood serum of adult inhabitants were within the reference range. However, in the examined women from Chulman, aged between 60 and 90 years, CEA indices were elevated up to $5.5 \mathrm{ng} / \mathrm{ml}$ in $1.6 \%$ of cases; CA $15-3$ up to $144 \mathrm{U} / \mathrm{ml}$ in $3.2 \%$ of cases. In $4.5 \%$ of women from Tommot, aged between 60 and 74 years, CEA levels were elevated to $7.4 \mathrm{ng} / \mathrm{ml}$.

In $22.2 \%$ of examined men aged between 45 and 59 years, from Chulman, CEA level was elevated to $10.4 \mathrm{ng} / \mathrm{ml}$ and PSA level was elevated up to $8.29 \mathrm{ng} / \mathrm{ml}$; in $7.7 \%$ of men aged between 60 and 74 years, PSA level was elevated up to $15.8 \mathrm{ng} / \mathrm{ml}$. Among the examined men from Tommot, these tumor markers were within the normal range.

Table 1.

The serum levels of TMs in men

\begin{tabular}{|c|c|c|c|c|c|c|}
\hline \multirow{2}{*}{ Age } & \multicolumn{2}{|c|}{ CEA(up to 5 ng/ml) } & \multicolumn{2}{c|}{ CA19-9(up to 35 U/ml) } & \multicolumn{2}{|c|}{ PSA(2.5-4.0 ng/ml) } \\
\cline { 2 - 7 } & Tommot & Chulman & Tommot & Chulman & Tommot & Chulman \\
\hline $18-44$ yrs & 0,9 & 2 & 0.1 & 0.1 & 0.1 & 0.5 \\
\hline $45-59$ yrs & 0.7 & 3.6 & 0.2 & 0.8 & 0.6 & 1.9 \\
\hline $60-74 \mathrm{yrs}$ & 1.1 & 2.7 & 0.1 & 0.2 & 0.5 & 2.2 \\
\hline $75-90 \mathrm{yrs}$ & & 3.1 & & 0 & & 1.9 \\
\hline
\end{tabular}

Table 2.

The serum levels of TMs in women

\begin{tabular}{|c|c|c|c|c|c|c|}
\hline \multirow{2}{*}{ Age } & \multicolumn{2}{|c|}{ REA(up to 5 ng/ml) } & \multicolumn{2}{c|}{ CA19-9(up to 35 U/ml) } & \multicolumn{2}{|c|}{ CA15-3(up to31.3 U/ml) } \\
\cline { 2 - 7 } & Tommot & Chulman & Tommot & Chulman & Tommot & Chulman \\
\hline 18-44 yrs & 0.5 & 1.8 & 2.6 & 0.1 & 3.5 & 20.0 \\
\hline 45-59 yrs & 0.5 & 2.4 & 0.9 & 0.3 & 5.2 & 18.9 \\
\hline 60-74 yrs & 1.1 & 2.4 & 3.6 & 0.4 & 7.1 & 25.5 \\
\hline $75-90 \mathrm{yrs}$ & 0.3 & 2.6 & 2.1 & 0.7 & 2.9 & 23.9 \\
\hline
\end{tabular}

\section{Discussion}

The data obtained lead to the conclusion that it is necessary to carefully monitor the health of individuals of certain ages: women from 60 years of age and men from 45 years, respectively. These age groups are a risk group for cancer.

Analysis of the literature shows that certain TMs are specific for certain groups of cancers. CEA is a tumorembryonic antigen produced in the tissue of the digestive tract of the embryo and fetus. After childbirth, the synthesis of CEA is suppressed; therefore, it is practically undetectable in the serum of healthy adults. This marker is found in very small quantities in some tissues of adults: in the intestines, liver and pancreas. CEA is a protein of the acute phase, so the level increases with various inflammatory and autoimmune diseases. A slight increase is recorded in smokers. The level of CEA is influenced by smoking and alcohol consumption. An elevated CEA level is found in colorectal cancer, stomach cancer, lung cancer, liver cancer, pancreatic cancer, and breast cancer.

As a type of tumor-associated antigen for gastrointestinal cancer, CA 19-9 is a sialylated derivative of the Lewis A blood group antigen. ${ }^{(6)}$ CA19-9 is detected in the epithelium of the gastrointestinal tract of the fetus. Minor amounts are found in adults in the cells of the pancreas, liver, and lungs. CA 19-9 is excreted in the bile; therefore, even with a slight cholestasis, its concentration in blood serum can increase significantly. As a tumor marker, it has sensitivity to pancreatic cancer (up to $82 \%$ ), liver cancer (up to $75 \%$ ), stomach cancer (up to $26 \%$ ), and colorectal cancer (25\%). CA19-9 has $79 \%$ to $81 \%$ sensitivity and $82 \%$ to $90 \%$ specificity for diagnosis of pancreatic ductal adenocarcinoma, ${ }^{(7)}$ with false-positive results observed in benign pancreaticobiliary diseases such as pancreatitis, cholangitis, and obstructive jaundice. ${ }^{(8-10)}$ Furthermore, CA19-9 is not expressed in $8 \%$ to $10 \%$ of the Caucasian population with the Lewis a-bgenotype, as the CA19-9 epitope is the sialylated Lewis A blood group antigen. ${ }^{(10,11)}$

CA 15-3 is an epithelial membrane antigen expressed on normal cells and found in serum. Elevated levels of this antigen are found in about $60 \%$ of preoperative breast cancer and $80 \%$ of advanced metastatic breast cancer. The CA 15-3 assay is not suitable as a diagnostic test because of its low sensitivity in stage I and II disease. CA15-3 is a marker for breast cancer, although in the absence of cancer CA 15-3 concentration can be significantly elevated in patients with vitamin B12 deficiency and in some healthy women during the menstrual cycle. Pancreatitis, Crohn's disease, ulcerative colitis, and benign gastrointestinal disease may also cause some elevation of CA 15-3. . $^{(2)}$

An elevated level of PSA is used for the early detection and therapeutic monitoring of prostate cancer $(\mathrm{PCa})$. The predominant immunoreactive forms of PSA, also known as isoforms, which have been identified in serum, include free (uncomplexed) PSA (fPSA) and PSA complexed to alpha 1-antichymotrypsin (PSA-ACT). It has been demonstrated that in men who have PCa, PSA-ACT is elevated. ${ }^{(13)}$ Contrarily, benign prostatic hyperplasia, a benign enlargement of the prostate, is associated with higher non-intact, free PSA serum levels. ${ }^{(14)}$

The results of tumor marker evaluations should be interpreted in conjunction with clinical data, and data of ultrasound and biopsy. 


\section{Conclusion}

Screening a population for tumor markers provides great opportunities for improving the management of cancer patients by enhancing the efficiency of detection and efficacy of treatment. Depending on the type of cancer, screening may be used in conjunction with clinical examination, data from ultrasound and a tissue biopsy. Because most tumor markers are not sensitive or specific enough, these tests are not well suited for screening the general population; however, a few may be used to screen people who are at high cancer risk (family history or specific risk factors for a particular cancer).

\section{Competing Interests} interests.

The authors declare that they have no competing

\section{References}

1. WHO. Cancer. Available from: https://www.who.int/ cancer/en/.

2. Beverly Handy. Clinical usefulness of tumor markers. Laboratory medicine. 2009;40(2):99-103.

3. Liu F, Du F, Chen X. Multiple tumor marker protein chip detection system in diagnosis of pancreatic cancer. World $\mathbf{J}$ Surg Oncol. 2014;12:333. doi: 10.1186/1477-7819-12-333.

4. Gion M, Cardinali G, Trevisiol C, Zappa M, Rainato G, Fabricio ASC. Indicators of inappropriate tumour marker use through the mining of electronic health records. J Eval Clin Pract. 2017;23(4):895-902. doi: 10.1111/jep.12754.

5. Kaprin AD, Starinsky VV, Petrov GV. Malignant neoplasms in Russia in 2017 (morbidity and mortality). M.:P.A. Hertsen Moscow Oncology Research Center-branch of
FSBI NMRRC of the Ministry of Health of Russia; 2018.

6. Magnani JL, Nilsson B, Brockhaus M, Zopf D, Steplewski Z, Koprowski H, Ginsburg V. A monoclonal antibody-defined antigen associated with gastrointestinal cancer is a ganglioside containing sialylated lacto-N-fucopentaose II. J Biol Chem. 1982;257(23):14365-9.

7. Ballehaninna UK, Chamberlain RS. The clinical utility of serum CA 19-9 in the diagnosis, prognosis, and management of pancreatic adenocarcinoma: an evidence based appraisal. $J$ Gastrointest Oncol. 2012;3(2):105-19. doi: 10.3978/j. issn.2078-6891.2011.021.

8. Steinberg W. The clinical utility of the CA 19-9 tumorassociated antigen. Am J Gastroenterol. 1990;85(4):350-5.

9. Duffy MJ. Carcinoembryonic antigen as a marker for colorectal cancer: is it clinically useful? Clin Chem. 2001;47(4):624-30.

10. Lamerz R. Role of tumour markers, cytogenetics. Ann Oncol. 1999;10 Suppl 4:145-9.

11. DiMagno EP, Reber HA, Tempero MA. AGA technical review on the epidemiology, diagnosis, and treatment of pancreatic ductal adenocarcinoma. American Gastroenterological Association. Gastroenterology. 1999; 117(6): 1464-84.

12. Al-Ibraheemi A, Dasgupta A, Wahed A. Pitfalls in Tumor Markers Testing. In: Dasgupta A. and Sepulveda J, editors. Accurate Results in the Clinical Laboratory. (A Guide to Error Detection and Correction). Elsevier Inc.; 2013:177-193.

13. Stenman UH, Leinonen J, Alfthan H, Rannikko S, Tuhkanen K, Alfthan O. A complex between prostate-specific antigen and alpha 1-antichymotrypsin is the major form of prostate-specific antigen in serum of patients with prostatic cancer: assay of the complex improves clinical sensitivity for cancer. Cancer Res. 1991;51(1):222-6.

14. Nagpal M, Singh S, Singh P, Chauhan P, Zaidi MA. Tumor markers: A diagnostic tool. Natl J Maxillofac Surg. 2016;7(1):17-20. doi: 10.4103/0975-5950.196135. 